\title{
Comunidad desobrada y comunismo literario en el pensamiento de Jean-Luc Nancy
}

\section{Inoperative Community and Literary Communism in the Thought of Jean-Luc Nancy}

\author{
Isabel Prats Noguera ${ }^{1}$
}

Resumen: La muerte de Dios y el derrumbe del comunismo despejan el terreno desde el que Jean-Luc Nancy trata de pensar lo común. Un pensamiento al que se le presentan las más diversas dificultades pues ya no hay principios trascendentales que funden lo diverso ni relatos míticos con los que identificarse. Sin embargo, es precisamente sobre este sustrato nihilista que lo común, el ser-juntos, se despliega y articula; es en este vacío donde las existencias singulares pueden mostrarse y exhibirse en su ser, pues es exponiéndose y ofreciéndose cuando efectivamente son.

De este modo, como trataremos de mostrar en el presente artículo, pensar el ser-con más allá del fundamento o el mito, sin caer por ello nuevamente en una onto-teo-política es el reto al que, según Nancy, estamos llamados. Una llamada que se propaga con la voz de la literatura y de la escritura y que nos impele a vivir en común asumiendo la finitud como aquello que nos sentimos obligados a compartir.

Palabras clave: Comunidad desobrada, comunismo literario, co-ontología, nihilismo.

Abstract: The death of God and the collapse of communism clear the ground from which Jean-Luc Nancy tries to think the common. A thought that faces the most diverse difficulties because there are no transcendental principles that ground the diverse or mythical stories with which to identify oneself. However, it is precisely on this nihilistic substrate that the common, the being-together, unfolds and articulates; it is in this void that singular existences can be shown and exhibited in their being-for it is by exposing and offering themselves when they actually are.

In this way, as we will try to show in the present article, to think about being-with beyond the foundation or the myth, without falling back into an onto-theo-politic for it is the challenge to which, according to Nancy, we are called. A call that spreads with the voice of literature and writing and that impels us to live together, assuming finitude as that which we feel obliged to share.

Keywords: Desobrated community, literary communism, co-ontology, nihilism.

\footnotetext{
${ }^{1}$ Investigadora predoctoral dentro del programa de doctorado en Pensamiento Filosófico Contemporáneo de la Universidad de Valencia. Actualmente realizando una tesis doctoral sobre la filosofía francesa contemporánea (ipratsno@alumni.uv.es).
} 


\section{EL NIHILISMO Y LA EXISTENCIA}

\section{Un diagnóstico de nuestro tiempo}

El diagnóstico epocal del que parte el pensamiento de Nancy advierte de la dramática situación en la que se encuentran las sociedades contemporáneas al verse asfixiadas por un avasallador avance del nihilismo que acaba con todo resorte comunitario y de vida en común. Capitalismo y democracia, ambos solidarios en este sentido, se pliegan a las exigencias de la lógica de la equivalencia, ya sea bajo la fórmula «todo vale igual»o siguiendo la máxima «todo es política». En uno y otro caso, el resultado es el mismo: una política burocratizada que paulatinamente va colonizando todas las esferas de la vida vaciándolas de alteridad y un funcionamiento social en el que todo se mide en términos monetarios. Tanto es así, que la misma existencia, concebida ahora como fuerza de trabajo, se incluye en el circuito económico bajo las leyes del mercado y pasa a contarse como una mercancía más. Esta sociedad de lo homogéneo conformaría lo que Nancy denomina un «democratismo de indistinción» ${ }^{2}$, esto es, una sociedad donde predominan la falta de valores o sentidos que guían la existencia.

Ante este escenario nada alentador, Nancy no se sitúa en el ámbito de la teoría política o de la politología, su análisis es estrictamente filosófico y alude directamente a la idea de sujeto que habita en el corazón de la democracia y de la sociedad entendidas en estos términos. Su gesto filosófico pasa pues por interrogar a la metafísica de la subjetividad que ha guiado el pensamiento moderno para subvertirla desde sus presupuestos fundamentales. Su crítica se concentra en la comprensión del hombre como individuo transparente, coincidente consigo mismo y cerrado en sí que ocupó el lugar central de dicha filosofía:

«El individuo -dirá Nancy- es representado como una entidad. La palabra "individuo" es como un átomo, infraccionable. El individuo es indivisible. Con esta indivisibilidad, ofrece la representación de una coherencia, una cohesión, una propiedad entera. Cada individuo es enteramente lo que es, pero no es solo lo que es. Es para sí, en sí, a sí. Se lo define implícitamente como una autosuficiencia. Y, desde el inicio, como exclusión de los otros»3.

Esta comprensión del hombre como átomo cerrado permite cuantificarlo, asirlo o definirlo. Todas las democracias liberales $-\mathrm{y}$ neoliberales- se ordenan en torno a la figura de este hombre-propietario, centrado y dueño de sí; él es el dato imprescindible para fijar las leyes y los reglamentos jurídicos; solo él pasa por el número y la cantidad. De esta manera, podemos decir que los átomos que componen el mosaico de las democracias contemporáneas son átomos inmanentes, sin clinamen, no se fusionan, no se tocan, no se rozan. Como apunta el pasaje citado, para el individuo, el otro y lo otro quedan relegados al lugar de lo indiferente e in-

\footnotetext{
2 Nancy, J.L. (2009). La verdad de la democracia, Madrid: Amorrortu, pág. 41.

${ }^{3}$ Nancy, op. cit. (2009). pp. 84 y 85.
} 
distinto. Si bien efectivamente sigue habiendo todo tipo de relaciones entre los diferentes individuos, no es menos cierto que las relaciones que imperan en este ordenamiento son siempre externas, mediadas y rescindibles cuando, tras un preciso cálculo de intereses, se concluye que no salen a cuenta. Así, uno puede regresar fácilmente al repliegue inmanente del que realmente nunca salió.

Habida cuenta de este diagnóstico, y tomando como punto de partida la diferencia óntico-ontológica y el desarrollo heideggeriano del ser-con, Nancy señala lo errado de la concepción del hombre como individuo o átomo sin clinamen. Al respecto, señala:

«Se plantea como autosuficiente algo, a alguien, que justamente no lo es en absoluto. Que, esencialmente, no lo es. Que es esencialmente en la relación»4.

En este pasaje Nancy apunta a una idea central de su pensamiento ya que, como se verá a continuación, todo su trabajo sobre la comunidad se apoya precisamente en una comprensión relacional de la existencia que escapa a la metafísica de la sustancia y a los derroteros a los que se ha visto conducida en el transcurso de la modernidad.

Sin embargo, cabe añadir que la tesis de Nancy no se queda en el desarrollo de Heidegger, sino que va más allá y plantea la necesidad de proseguirlo en la dirección de una «ontología del ser-con» ${ }^{5}$ o «co-ontología» que no entienda la coexistencia precediendo a la existencia, sino que, al contrario, la considere previa y originaria. Esta inversión del orden responde a esa idea plural de la existencia, sin por ello entenderla como la suma o el resultado de las distintas esencias reunidas. La relación antecede a las singularidades constituyéndolas y acompañándolas en su devenir; no en vano, el propio paso por el lenguaje y la comunicación nos pone ante la imposibilidad ontológica y epistemológica de promulgar un solipsismo filosófico. Será en estos términos en los que Nancy formule la premisa ontológica mínima sobre la construye su enfoque:

«El sentido del ser no ser realiza en el Dasein para ser luego "comunicado" a otros: su realización es idéntica a ser-con. O incluso: el ser se realiza como "con". [...] El ser es comunicación» 7 .

De este modo, lejos de la idea del hombre que puede optar por desoír los reclamos de una existencia siempre compartida y que prefiere mantenerse en una reclusión inmanente, el ser singular al que apela Nancy es una existencia abierta que solo es fuera-de-sí, al exponerse, compartirse y comunicarse. Su finitud la lleva

\footnotetext{
${ }^{4}$ Nancy, op. cit., (2009). pág. 85.

${ }^{5}$ Nancy, J.L. (2006). Ser singular plural, Madrid: Arena Libros, pág. 100.

${ }^{6} \mathrm{Nancy}$, op. cit. (2006). pág. 58.

7 Nancy, op. cit. (2006). pág. 43. Cabe tener en cuenta que, en este punto, Nancy no solo está siguiendo la senda heideggeriana, sino que también se apoya en el pensamiento de Bataille y su concepción de la existencia como comunicación. Para este autor, el aislamiento de los seres individuales no sería sino un engaño o una ilusión de la que uno ha de despertar para perderse en la entrega al otro.
} 
a ello, la angustia de su insuficiencia la impele a salir de sí. Como puede advertirse, la audacia de Nancy en este punto consiste precisamente en proponer una ontología dinámica y relacional; una ontología que abandona las nociones estáticas y esencialistas en un esfuerzo por llevar la ontología más allá de los límites trazados por la filosofía moderna. Cabe tener presente, además, que uno de los movimientos filosóficos a los que contrapone su pensamiento es precisamente el gesto fundador con el que se dio inicio el proyecto moderno: el fatídico impulso que lleva, no ya a eludir la ausencia de un fundamento último, sino a forzar un cierre con el fin de lograr algo de estabilidad en medio de la más absoluta indeterminación existencial.

En consecuencia, el ser un nosotros antes que un yo, el tener que pronunciar nos sumus antes que ego sum, hace del hombre un ser inacabado que no se deja atrapar en definiciones restringidas propias de los humanismos o antropologismos. La existencia, tal y como la entiende Nancy, es una existencia que es en el límite donde queda expuesta, este límite es precisamente el rastro de la finitud que deja su huella en el hombre, transgredirlo significaría dejar-de-ser y no alcanzarlo no-llegar-a-ser.

\section{La salida del nibilismo}

Esta comprensión relacional de la existencia ya abre una salida del escenario nihilista esbozado al comienzo del artículo. ${ }^{8}$ El camino que así se abre escapa a la doble posibilidad de o bien quedar suspendido en el impasse entre el nihilismo activo -la destrucción de los valores- y el nihilismo pasivo -la extinción interminable de todo lo que hay-, o bien esperar a la venida del Anticristo o el Antinihilista que salve el sentido de la destrucción. Nancy no se conforma ni con una ni con otra posibilidad, no opta ni por mantenerse en los confines del nihilismo sea en la forma que fuere, ni por retornar al amparo trascendental de la teología bajo la figura mítica del héroe o del salvador. Su planteamiento abre una tercera posibilidad.

Paradójicamente, el movimiento que propone para salir del atolladero nihilista busca en primer lugar ir hasta el fondo mismo del nihilismo yendo más allá de la mediación entre la extinción y la destrucción. Lo que se busca es poner fin a la creencia nihilista sin tener que reemplazarla por otra diferente. De este modo, en las profundidades del nihilismo, cuando este ha cubierto por entero el mapa de lo existente, aparece lo que, estando en su fondo, ya siempre lo ha excedido y superado, a saber, la existencia misma en cuanto afirmación que se eleva sobre la nada en la que está suspendida. Esta afirmación representa precisamente la cara opuesta del nihilismo, pues si bien la lógica de la equivalencia conduce a descrear mundo, es decir, a disolver todos los sentidos y valores dejando a su paso una masa informe e inmanente, la afirmación de la singularidad no es sino la afirmación de un valor

\footnotetext{
${ }^{8}$ Reparamos en que el planteamiento de Nancy supone una reconsideración de la relación que tradicionalmente ha unido a la teoría y a la praxis, como si fueran dos elementos separados que, eventualmente, podrían ponerse en relación. Por su parte, afirmará: «Entrar en este pensamiento ya es actuar. Es situarse en la praxis mediante la cual se produce un sujeto transformado más que un producto conformado, un sujeto infinito más que un objeto terminado». (Nancy, op. cit. (2009), pág. 55)
} 
inconmensurable. Un valor que, escapando a toda equivalencia y jerarquía, logra dar sentido:

«Tan solo así se sale del nihilismo: no con la reactivación de valores, sino con la manifestación de todos en un marco en el cual la "nada" significa que todos valen inconmensurablemente, absolutamente e infinitamente»".

Precisamente esta afirmación conforma el desafío al que nuestro presente ha de enfrentarse: pensar desde el nihilismo más allá del nihilismo, salvaguardar la distinción frente a toda tentativa uniformadora y relativista sin por ello caer en los brazos de un nuevo sistema axiológico. Siguiendo la estela de este pensamiento, Nancy dibujará el espacio de la comunidad desobrada, un espacio vacío en el que las singularidades se exponen y comparten, donde pueden afirmarse en un frágil movimiento perpetuo que no funda, pero que no por ello deja de ser creador.

\section{LA COMUNIDAD DESOBRADA ${ }^{10}$}

Como veremos a continuación, la idea de comunidad desobrada surge como el correlato necesario del enfoque co-ontológico expuesto hasta aquí, así como de la necesidad urgente de abrir una brecha que ponga en suspenso la marcha incansable del nihilismo. Así pues, siguiendo el planteamiento esbozado, Nancy denomina «política democrática» ${ }^{11}$ a aquella que está a la altura de la comprensión de la existencia como ser-fuera-de-sí. Sería una política que, lejos de inundar todos los recovecos y esferas de la vida en un movimiento inmanente, se retira.

Cabe advertir, no obstante, la particular concepción que Nancy tiene de este concepto de «retirada», que elaboró y desarrolló junto con su colega LacoueLabarthe en el "Centro de investigaciones filosóficas sobre lo político", inaugurado en 1980. Al aludir a "retirada", ambos remiten a un doble gesto en el que la políti$\mathrm{ca}$, en su mismo retirarse, re-traza $[\text { retrait }]^{12}$ un espacio vacío que es propiamente el de la comunidad y que la política habría de asegurar y preservar en su indeterminación. Este espacio puede ser concebido como una suerte de fisura que despeja un no-lugar donde las singularidades pueden efectivamente dar rienda suelta a su inherente desbordamiento pasional, comunicarse y exponerse en una articulación sin

\footnotetext{
${ }^{9}$ Nancy, op. cit. (2009). pág. 45.

${ }^{10}$ Cabe advertir que, en cierto momento de su trabajo, para referirse a la misma experiencia, Nancy sustituye la noción de comunidad por la de ser-juntos o ser-con. El cambio responde a su propósito de marcar distancia respecto a las propuestas comunistas o comunitaristas, así como complacer a «amigos filósofos como Jacques Derrida» (Nancy, op. cit. (2009). pág. 82) que no estaban conformes con la palabra comunidad. En este artículo se seguirá empleando comunidad -del mismo modo que ser-con o ser-juntos- pues es el término empleado en los libros consultados.

11 Nancy, op. cit. (2009). pág. 57.

${ }^{12} \mathrm{El}$ verbo retrazar es empleado aquí como recurso. El sustantivo retrait en francés se traduce generalmente por retirada, sin embargo, trait también puede referir a trazo. Así pues, con retrait, se hace alusión al doble movimiento de una retirada que, en su retirarse, re-traza o dibuja límites. Cf. Nancy, J.L. y Lacoue-Labarthe, P. (2012). "Retrazar lo político", en Nombres: Revista de filosofía, 26, pp. 51-67.
} 
principio ni fin. Esta y no otra es, a ojos de Nancy, la labor de la política. Su cometido no será dirigir a las existencias singulares dotándolas de un cometido o contenido, de ahí que hable de vacío o no-lugar y que la salida sea desde el nihilismo.

Siguiendo esta idea, cabe hacer hincapié en una preocupación que atravesará toda la obra de Nancy y es que la comunidad desobrada no ha de ser confundida con una comunidad de muerte ${ }^{13}$. Con esto lo que se quiere decir es que las singularidades que la componen no han de sacrificarse en favor de una unión que conforme un cuerpo político, como tampoco han de plegarse a la consecución de una empresa o proyecto. Si así fuera, la comunidad se vería conducida de nuevo al nihilismo, a una identificación que une excluyendo y que, llegando hasta el extremo, aboca directamente al exterminio de lo que no se deja subsumir.

$\mathrm{El}$ recuerdo viviente de los totalitarismos del siglo XX es precisamente una de las razones que disuade a Nancy de optar por la tentativa de fundar la comunidad, de darle un sentido o un proyecto. Según el autor, aquella comunidad que aspira a una comunión bajo una identificación mítica con el Hombre, la Historia o el Pueblo, termina aniquilando la existencia procurándole un encaje en un proyecto megalómano de convergencia en lo trascendental. La terrible huella que los totalitarismos han dejado en la historia nos obliga a rehusar cualquier recurso a nuevos mitos o relatos que pretenden fundar la comunidad dándole un origen y un fin. Nuestro presente es aquel en el que los sistemas de principios han quedado atrás y hemos de arreglárnoslas en la inestabilidad de la existencia para pensar lo común, inaugurando con ello el pensamiento de un nuevo orden.

En este punto podemos decir que el pensamiento de lo común puesto en juego por Nancy tiene muy presente el precepto del tacto y lo incorpora como principio fundamental. ${ }^{14}$ Este principio se caracteriza fundamentalmente por no obviar ni combatir la distancia que separa a las singularidades en un vano intento de cerrar lo ya de por sí abierto o de acabar lo que se presenta como inacabable. Esta lógica del tacto respeta y no transgrede la distancia infranqueable de las existencias singulares que, al exponerse, lo hacen siempre sobre el límite que las retira. Es por esto que Nancy coloca la idea de desobramiento [déscouvrée] junto a la de comunidad.

En primer lugar, cabría precisar que cabe entender por desobramiento en este contexto pues no son pocos los equívocos que esta noción ha traído consigo por

13 Por este motivo, no empleará nociones como confusión o continuidad que tan habituales son en la obra de Bataille, ni le seguirá en su desarrollo de la comunidad de los amantes. «Detecté en su comunidad de amantes la aspiración a una "comunión" esa palabra no es habitual en Bataille, sin duda, pero sí encontramos «confusión» y «continuidad», que caracterizan el paso al límite, en el abrazo, de individuos distintos cuyo objetivo común es una fusión en última instancia imposible (y en relación con la cual el erotismo sigue siendo una comedia, igual que, por su parte, el sacrificio en el que el sacrificador mismo no desaparece). Yo pensaba, en consecuencia, que esta aspiración a la comunión paralizaba a Bataille en su búsqueda de una política de igual modo que antes lo había desviado de una acción política en que la propia política se había consumido (se habría consumido consumándose). En consecuencia, me esforzaba (dudando sobre si llamar todavía "política" a aquello de lo que se trataba) por esbozar la idea de una política «que se orientara al «desobramiento" de su comunicación.» (Nancy, J.L. (2001). La comunidad desobrada Madrid: Arena Libros, pp. 51-52).

${ }^{14} \mathrm{El}$ motivo del tacto puede ser entendido como un hilo vertebrador de la obra nancyana. No en vano Derrida se referirá a Nancy como «el más grande pensador del tacto, de todos los tiempos.» (Derrida, J. (2011). El tocar, Jean-Luc Nancy, Madrid: Amorrortu, pág. 23) 
su difícil traducción. Nancy toma déscuvrée del ámbito literario, concretamente del pensamiento de Maurice Blanchot, para dar cuenta de

«aquello por lo cual la obra no pertenece al orden de lo acabado ni tampoco de lo inacabado: nada le falta y no tiene culminación..» ${ }^{15}$

De este modo, si bien déscuvrée es traducido en ocasiones por «inoperancia» ${ }^{16}$, no cabría entender por ello una cierta incapacidad o ineficacia para el obrar, sino una renuncia a hacer obra, una aceptación de su inherente incompletud e incluso una resistencia tenaz al cierre.

Así pues, trasladando esta idea a la comunidad, esta no sería la puesta en marcha de una empresa política o de otra índole, sino que cabría concebirla más bien como una experiencia cotidiana de ser-en-común, una experiencia inasible pues no hay certeza que la alcance o concepto que la restringa. Una vivencia desbordante cuya llegada no se deja anunciar en decálogos o manifiestos, como tampoco responde a un programa político. De hecho, no sería posible determinar su origen o su final porque esta experiencia comunitaria no alude sino a la comunicación permanente entre existencias fracturadas que se sienten impelidas a compartirse en el afuera.

Como hemos comentado más arriba, la cuestión de fondo que subyace a esta manera de caracterizar lo común supone una comprensión dinámica de la ontología que se sitúa más allá de la metafísica de la presencia para tratar de pensar la transitividad del ser. Es por esta razón que al apelar al ser-en-común como elemento estructural de la existencia singular, Nancy pone el acento en el en o en el entre y no en el común:

«No hay comunión, no hay ser común, hay el ser en común. Toda la ontología, desde el momento en que es esta lógica del ser en sí como ser a sí, se reduce de este modo al en-común del $a$-sí. Esta "reducción", o esta reevaluación total, o esta revolución de la ontología es sin duda lo que nos acaece, aún mal advertido, desde Hegel y Marx, Heidegger y Bataille. El sentido del ser no es común -sino que el en-común del ser transita todo el sentido. $\mathrm{O}$ aún: la existencia no es más que para ser compartida. Pero esta partición -que se podría designar como la aseidad de la existencia- no distribuye una sustancia ni un sentido común. No reparte más que la exposición del ser, la declinación del sí-mismo, el temblor sin rostro de la identidad expuesta: nos reparte» ${ }^{17}$.

Como puede advertirse, el ser, que acontece en la compartición, no lo hace como resultado final de un encuentro de diferentes existencias, pues nada subsiste

\footnotetext{
${ }_{15}$ Nancy, J.L. (2016). La comunidad descalificada, Madrid: Avarigani Editores, pág. 47.

16 Debido precisamente a las dificultades de traducción, La communauté déscuvrée (1983), título del primer ensayo de Nancy sobre la comunidad, ha sido traducido al español de dos modos distintos. La traducción de Juan M. Garrido publicada en LOM Ediciones lleva por título La comunidad inoperante, pero un año después (2001) Pablo Perera, en colaboración con Isidro Herrera y Alejandro del Río, optará por La comunidad desobrada (Arena Libros).

${ }^{17}$ Nancy, op. cit. (2001). pág. 156.
} 
o preexiste a su exposición unas a otras; bien al contrario, el ser comparece en el comunicarse de los seres finitos, en la articulación ilimitada de las existencias expuestas en el exterior donde propiamente son. Según este enfoque, la comunidad ha de ser entendida como la perpetua resistencia a la inmanencia, una negativa a su clausura. De ahí que Nancy hable de comunidad desobrada como «comunidad de la articulación $»^{18}$ o del ser-en-común como «resistencia a la fusión» ${ }^{19}$.

\section{Pensamiento y COMUNIDAD, EL COMUNISMO LITERARIO}

La voz de la comunidad

En concordancia con su negativa a clausurar el sentido de la existencia o de la comunidad, Nancy señala la tensión insoslayable que afecta al pensamiento en su intento de habérselas con la experiencia del ser-en-común. No hay palabras, no hay conceptos o expresiones que agoten su sentido. Así, se referirá al vano intento de alcanzar algo así como "el fin de la filosofía" 20 en el sentido de una filosofía cumplida, acabada, que ha cancelado el sentido de la comunidad, traicionándola groseramente. Desde luego, esta no ha de ser la relación entre comunidad y filosofía, ya que el entendimiento intenta poner límites a lo que, de entrada, se presenta como ilimitado, a lo que no tiene acabamiento, ni origen ni final. El sentido y el pensamiento no coinciden y, cuando este último cree haber dado con la categoría que fijaría la experiencia del ser-juntos, esta ya ha escapado sin haberse dejado reconocer en palabras que siempre desborda.

Así pues, en este punto la pregunta de Nancy es clara:

«Cómo pensar eso que, literalmente, afecta a todos nuestros cuerpos, cuando ya no es posible recurrir a las fundaciones o a los tótems de los mundos desaparecidos? Esta pregunta excede, por definición, cualquier política, cualquier eclesiología, cualquier nacionalismo o comunitarismo y, más aún, cualquier clase de solidaridad, de ayuda mutua o de afán colectivo. Esta es la pregunta cuyo aguijón, exasperación o suplicio conserva la palabra comunismo, desde hace más de dos siglos, conservando al mismo tiempo también una expectativa y una exigencia» ${ }^{21}$.

Debido a su compromiso con esta expectativa y esta exigencia, y sin obviar en modo alguno las dificultades que encuentra el pensamiento a la hora de dar alcance a lo que rebasa a la teoría, Nancy se niega a capitular e insiste en «movilizar palabras $»^{22}$ para señalar, en el límite de lo expresable, la experiencia del ser-encomún, que es la experiencia en la cual y por la cual somos. Esta labor de decir lo

\footnotetext{
${ }^{18}$ Nancy, op. cit. (2001). pág. 142.

${ }^{19}$ Nancy, op. cit. (2001). pág. 43.

${ }^{20} \mathrm{Nancy}$, op. cit. (2001). pág. 158.

${ }^{21}$ Nancy, op. cit. (2001). pág. 34.

22 Nancy, op. cit. (2001). pág. 52.
} 
(in)decible es la que ocupa al comunismo literario que encarna «la partición de la comunidad en y por su escritura, su literatura» ${ }^{23}$.

En este punto cabe hacer una precisión pues, tal y como él mismo advierte, Nancy emplea comunismo literario en un gesto más bien provocativo con el que pretende rendir homenaje a las aportaciones al pensamiento de lo común que en un momento concreto hicieron tanto la filosofía comunista como la literatura y los escritores. Sin embargo, renuncia muy pronto a seguir utilizando ese nombre:

«Habría [...] una tarea indisociablemente, y tal vez incluso indiscerniblemente "filosófica" y "comunitaria" [...] que sería la tarea de exponer el inexponible en. [...] Esto puede inmediatamente evocar la figura de una "comunidad pensante", de una abadía de Thélème o de un cenáculo romántico que se concibe como república (y como república de reyes [...]), o algo así como un "comunismo literario" (me he servido hace poco de esta expresión, pero su equívoco me hace renunciar a ella: no se trata de una comunidad letrada [...]). [...] El envite sería aquel $[\ldots]$ que consiste en exponerse a la partición del enn ${ }^{24}$.

La idea que pretende trasladar Nancy es precisamente la de una comunidad de la articulación que no se entienda en términos operatorios. En este sentido, hablará de literatura o de escritura en referencia a una experiencia que es propiamente la experiencia comunitaria: la vivencia del saberse expuesto al afuera y ofrecido a los demás.

Con todo, cabe advertir que las obras que son abandonadas a la comunidad también se encuadran en esta comprensión no funcionalista ni tendente a resultados. En ellas no prima el mensaje ni importa el contenido, la cuestión radica en la compartición, una compartición que desde luego no se limita a la obra literaria, sino que acompaña al pensamiento, a las artes, a la ciudad y a cualquier rastro de existencia en-común. Lo que todas estas obras comparten de un modo u otro es precisamente su desobramiento y es esto lo que las convierte en obras comunitarias. Así pues, sería un error comprenderlas bajo el rótulo de mercancías y en ningún caso cabría imaginárselas como productos que pasan de mano en mano o que se cuentan entre otros bienes culturales. Nuevamente, hay que abandonar la idea de completud o totalidad. Las obras de la comunidad son aquellas cuyo sentido no solo no está cerrado, sino que no puede ser clausurado. Es una escritura en y por el límite y es por esto mismo que son abandonas a la comunicación y repartidas una y otra vez.

Llevando este planteamiento más allá, Nancy llega a afirmar que la estructura y naturaleza del ser singular es exactamente la de «un ser de escritura» o «un ser literario $»^{25}$. Esta caracterización entronca con su enfoque co-ontológico: del mismo modo que la singularidad, para Nancy, es una existencia exiliada que es

\footnotetext{
${ }^{23}$ Nancy, op. cit. (2001). pág. 53.

24 Nancy, op. cit. (2001). pág. 172.

25 Nancy, op. cit. (2001). pág. 144.
} 
arrojada al afuera del que no habrá retorno u oportunidad de recobrarse, la escritura será siempre ex-critura ${ }^{26}$. Se escribe para quien no comparece, para otro que puede que venga. La literatura es, por tanto, un distanciado toque entre seres singulares no-coincidentes que no pueden dejar de compartir su acabamiento y finitud. La ex-critura expone «el límite sobre el que la comunicación tiene lugar» ${ }^{27}$, un límite que no puede ser traspasado si ha de haber toque, y no fusión, pero que, al mismo tiempo, ha de ser alcanzado para que los cuerpos puedan tocarse y no se mantengan recluidos en un cierre inmanente. Por este motivo, al comunismo literario se le impone una doble exigencia:

«Desafiar a la inmanencia sin habla y a la trascendencia de un Verbo» ${ }^{28}$.

\section{La cotidianidad de la experiencia comunitaria}

A lo dicho hasta aquí cabe añadir una peculiaridad de la escritura que acompaña a la idea de comunidad desobrada nancyana. La literatura nos recuerda no solo que nuestra existencia es común, sino que ya siempre ha sido así y que no puede ser de otro modo. En este punto, bien pudiera decirse, como ya entrevió Bataille ${ }^{29}$, que la literatura no es sino el envío de lo conocido a lo desconocido, un tránsito que va del sentido común a la novedad y al acontecimiento. La obra literaria extraería lo que ha sido inscrito en el ámbito del conocimiento discursivo y del ordenamiento de lo dado para mostrarlo en su existencia desnuda, una existencia que siempre queda más acá o más allá de lo que el sentido común establece, pues es ella misma la que da sentido, es al exponerse donde el ser acece. Lo cotidiano, lo puramente anodino y pasado por alto desde la lógica de la equivalencia y de lo igual, la literatura nos lo muestra fuera de ese marco. A este respecto Nancy sostiene:

«Se dirá que me pierdo en una micrología. No cabe duda de que estamos en lo infinitamente pequeño y en lo insignificante. Sin embargo, es ahí que comienza la relación: una "impresión" la precede siempre, o más bien una "impresión" ya siempre la ha comprometido, antes de que nos comprometamos en lo que ordinariamente llamamos una "relación" digna de este nombre. Y quizá precisamente nos engañamos cuando pensamos "una relación digna de este nombre"»"

Así pues, nuestra existencia ya siempre es en-común, pues es la existencia de un ser «literario». En el devenir cotidiano en el que estamos inmersos no aprecia-

\footnotetext{
${ }^{26}$ En un epígrafe de Corpus titulado precisamente Escríbase al cuerpo, Nancy hace unas observaciones que, a nuestro parecer, arrojan luz sobre la relación de la literatura y la escritura con la comunidad: «Escribir es el pensamiento dirigido, enviado al cuerpo, a lo que lo separa, a lo que lo hace extraño». Por esta razón, el pasaje habla de la ontología del cuerpo como "excripción del ser" y del cuerpo como "ser-excrito" (Nancy, JeanLuc, (2016), Corpus (nueva edición aumentada), Madrid: Arena Libros, pág. 19).

27 Nancy, op. cit. (2001). pág. 124.

28 Nancy, op. cit. (2001). pág. 147.

${ }^{29}$ Bataille, G. (1973). La experiencia interior, Madrid: Taurus, pág. 144.

${ }^{30}$ Nancy, J.L. (2011). "Être-avec et démocratie- Ser-con y democracia (Bilingüe)", en Revista Pléyade, 7, pp. 11-31.
} 
mos el acontecer plural de lo corriente, sin embargo, no hay nada más que la afirmación de la singularidad a cada momento y a cada instante, nada más que el inadvertido acontecer del ser en la comunicación. Esto es lo que dota de sentido a una existencia cuyo trasfondo es la nada. Un gesto que carece en sí mismo de sentido, pero no por ello deja de crear mundo. $\mathrm{Y}$ es precisamente la escritura la que nos permite recabar en ello al ofrecer a la comunidad la comunicación de esta partición que, de otro modo, pasaría desapercibida. ${ }^{31}$

Para concluir y habida cuenta de lo expuesto hasta aquí, no es de extrañar que Nancy hable de la $\langle\text { resistencia comunista literaria }\rangle^{32}$ pues la literatura ilumina una salida a la eterna repetición de lo igual que rige las sociedades capitalistas. El comunismo literario muestra un afuera de esa lógica que se pretende incuestionable exponiendo la insuficiencia de su comprensión de lo humano y lo limitantes que resultan sus principios esenciales. Desde luego, será una indicación precaria, en el sentido de que escapa siempre al pensamiento que trata de asirla en conceptos y clausurar su sentido, pero no por ello menos real o menos verdadera. Lo que señala la literatura es la experiencia en-común como algo que ya siempre estuvo ahí y que no deja de acaecer.

\section{REFERENCIAS BIBLIOGRÁFICAS}

Bataille, G. (1973). La experiencia interior, Madrid: Taurus.

Derrida, J. (2011), El tocar, Jean-Luc Nancy, Madrid: Amorrortu.

Heidegger, M. (2012), Ser y tiempo, 3a ed., Madrid: Trotta.

Nancy, J. L. (1996), "La existencia exiliada", Archipiélago: Cuadernos de crítica de la cultura, 26-27, pp. 34-40.

- (2001). La comunidad desobrada, Madrid: Arena Libros.

- (2006). Ser singular plural, Madrid: Arena Libros.

- (2008). "Tres fragmentos sobre el nihilismo", en R. Esposito, C. Galli y V. Vitiello (comps.), Nibilismo y política: con textos de Jean-Luc Nancy, Leo Strauss, Jacob Taubes, Buenos Aires: Manantial, pp. 15-33.

- (2009). La verdad de la democracia, Madrid: Amorrortu.

- (2011). "Être-avec et démocratie- Ser-con y democracia (Bilingüe)", Revista Pléyade, 7, pp. 11-31.

- (2016). Corpus (nueva edición aumentada), 3a ed., Madrid: Arena Libros.

Nancy, J. L. y Bailly, J. C. (2014). La comparecencia, Madrid: Avarigani Editores.

Nancy, J.L. y Lacoue-Labarthe, P. (2000). "La 'retirada' de lo político", Nombres: Revista de filosofía, vol. 10, núm. 15, p.p. 33-46.

- (2002). El mito nazi, Barcelona: Anthropos.

- (2012). "Retrazar lo político", Nombres: Revista de filosofía, 26, pp. 51-67.

${ }^{31}$ Nancy, J. L. y Bailly, J. C. (2014). La comparecencia, Madrid: Avarigani Editores, pág. 93.

32 Nancy, op. cit (2001). pág. 148. 